\title{
PENGARUH LAYANAN KONSELING KELOMPOK TERHADAP INTERAKSI SOSIAL SISWA SMA NEGERI 9 KOTA BENGKULU
}

\author{
Intan Permata Sari, Pudji Hartuti, Illawaty Sulian \\ Prodi Bimbingan dan Konseling Fakultas Keguruan dan Ilmu Pendidikan \\ Universitas Bengkulu \\ Intanpermata1997@yahoo.com, pudjihartuti@unib.ac.id,illawaty@unib.ac.id
}

\begin{abstract}
ABSTRAK
Penelitian ini bertujuan untuk mendeskripsikan pengaruh layanan konseling kelompok terhadap interaksi sosial siswa kelas XI IPS 3 Di SMA Negeri 9 Kota Bengkulu. Metode yang digunakan dalam penelitian ini adalah metode eksperimen dengan desain one group pre-test post-test design. Sampel penelitian ini sebanyak 8 orang siswa dari XI IPS 3 di SMA Negeri 9 Kota Bengkulu. Sampel diambil dengan teknik purposive sampling. Hasil yang diperoleh dalam penelitian ini menunjukkan ada pengaruh yang signifikan layanan konseling kelompok terhadap interaksi sosial siswa. Hasil dari perhitungan uji Wilcoxon dengan nilai Z $-2,524$ dengan taraf signifikansi $0,012<0,05$. Artinya, terdapat pengaruh layanan konseling kelompok terhadap interaksi sosial siswa kelas XI IPS 3 di SMA Negeri 9 Kota Bengkulu.
\end{abstract}

Kata kunci : interaksi sosial siswa, konseling kelompok

\section{THE INFLUENCE OF A GROUP COUNSELLING SERVICE ON THE STUDENT SOCIAL INTERACTION AT SMA NEGERI 9 KOTA BENGKULU}

\begin{abstract}
This study aimed at describing the influence of a group counselling service on the students social interaction in class XI IPS3 on the students social interaction in class XI IPS3 at SMA Negeri 9 Kota Bengkulu. Experiment method with one group pre-tes post-test design was used in this research. The sample of this research were 8 students from XI IPS3 at SMA Negeri 9 Kota Bengkulu. The sample were taken by purposive sampling teachnique. The result of this reasearch showed that the group counselling service influenced significantly the students social interaction. The result was counted by Wilcoxon test showed Z -524 value with significantion level $0,012<0,05$. It meant that there is the influence of the group counselling service on the students social interaction in class XI IPS3 at SMA Negeri 9 Kota Bengkulu.
\end{abstract}

Keywords : student social interaction, group counselin 


\section{Pendahuluan}

Manusia adalah makhluk sosial yang mempunyai dorongan sosial untuk berhubungan dengan orang lain. Akibat motif sosial tersebut mereka cenderung mencari orang lain untuk mengadakan interaksi. Dengan begitu terjadilah interaksi seseorang antara satu dengan yang lain. Hal ini sesuai dengan pendapat bahwa "Interaksi sosial ialah hubungan antara individu yang satu dengan individu yang lain dan dapat saling mempengaruhi sehingga dapat terjadi hubungan timbal balik" (Walgito,1999: 57). Hubungan interaksi dapat terjadi antar individu dengan individu, individu dengan kelompok, kelompok dengan kelompok.

Apabila dua orang bertemu, interaksi sosial dimulai pada saat itu. Individu saling bertegur, berjabat tangan, berbicara atau bahkan mungkin berkelahi. Aktivitas seperti itu merupakan bentuk interaksi sosial. Walaupun bertemu tidak saling berbicara atau tidak saling menukar tanda-tanda, interaksi sosial telah terjadi, karena masing-masing sadar ada pihak lain yang menyebabkan perubahan-perubahan dalam perasaan maupun saraf orang-orang yang bersangkutan, yang disebabkan oleh misalnya bau keringat, minyak wangi, suara berjalan, dan sebagainya (Soekanto, 2010: 55).

Layanan konseling kelompok yaitu layanan bimbingan dan konseling yang memungkinkan peserta didik memperoleh kesempatan untuk pembahasan dan pengentasan permasalahan yang dialaminya melalui dinamika kelompok. Dinamika kelompok adalah suasana yang hidup, berdenyut, bergerak, berkembang, ditandai dengan adanya interaksi antar sesama anggota kelompok (Sukardi, 2008: 68).

Proses pengentasan masalah individu dalam konseling kelompok mendapatkan dimensi yang lebih luas, kalau dalam konseling perorangan klien hanya memetik manfaat dari hubungannya dengan konselor saja, dalam konseling kelompok klien memperoleh bahan-bahan bagi pengembangan diri dan pengentasan masalahnya baik dari konselor maupun rekan-rekan anggota kelompok (Prayitno dan Amti, 2013: 311).

Terkait dengan perkembangan interaksi sosial siswa, hal seperti ini harus mendapat perhatian khusus dari guru bimbingan dan konseling di sekolah. Pelayanan bimbingan dan konseling mempunyai ruang lingkup yang cukup luas dan dapat dilihat dari berbagai segi, salah satu diantaranya yaitu segi fungsi yang mencakup: pemahaman, pencegahan, pengentasan, dan pemeliharaan. Layanan yang terdiri dari sepuluh jenis layanan, disinilah kompensasi yang dimiliki guru bimbingan dan konseling sangat dibutuhkan (Riansyah, 2017: 48). 
Permasalahan yang ditemukan di lapangan bahwa berdasarkan hasil sosiometri yang telah dilaksanakan di kelas XI IPS 3 SMAN 9 Kota Bengkulu. Siswa yang memiliki interaksi sosialnya rendah dikarenakan siswa kurang memiliki hubungan sosial yang baik seperti sikap dan perilaku siswa yang dianggap oleh teman-temannya tidak berkenan dihati, mengganggu kenyamanan, membuat orang lain tersinggung dan kurang bisa bersosialisasi dengan baik. Terdapat siswa yang berkelompok dalam kelas membuat siswa yang lain menjadi takut untuk bergabung, adapula siswa yang merasa canggung pada saat berbaur dengan teman yang lainnya. Inilah yang akhirnya membuat mereka terisolir di kelas, tidak memiliki banyak teman, dijauhi oleh teman-teman lainnya dan pada akhirnya membuat mereka tidak nyaman lagi belajar di kelas dan terasing dari lingkungan sosialnya. Hal ini sangat memprihatinkan karena pada hakikatnya tujuan siswa ke sekolah adalah untuk menuntun ilmu, belajar dengan nyaman dan berinteraksi dengan banyak teman maka dari itu perubahan sikap dan prilaku harus dilakukan oleh para siswa agar permasalahan ini tidak terus berlanjut.

Mengingat di lingkungan sekolah jumlah siswa yang begitu banyak dan mempunyai karakteristik yang berbeda-beda, mereka perlu belajar bergaul dan memahami satu sama lain dalam melatih kemampuan untuk menumbuhkan kepercayaan diri dalam lingkungan sosial yang lebih luas. Fenomena ini sebenarnya bukan masalah terjadinya konflik di antara mereka melainkan memang ada siswa yang mengalami masalah sosial yang berbeda atau lebih rendah kemampuan interaksinya dibandingkan dengan temannya. Untuk itu perlu diupayakan agar mereka yang bermasalah dapat mengatasi permasalahan tersebut, yaitu melalui layanan konseling kelompok.

Berdasarkan latar belakang tersebut, dapat dirumuskan permasalahan dalam penelitian ini adalah sebagai berikut :

1. Bagaimana interaksi sosial siswa sebelum diberikan layanan konseling kelompok di SMA Negeri 9 Kota Bengkulu?

2. Bagaimana interaksi sosial siswa sesudah diberikan layanan konseling kelompok di SMA Negeri 9 Kota Bengkulu?

3. Apakah ada pengaruh layanan konseling kelompok terhadap interaksi sosial siswa di SMA Negeri 9 Kota Bengkulu? 


\section{Metode Penelitian}

Metode penelitian ini menggunakan penelitian kuantitatif dengan menggunakan metode eksperimen jenis Pre-eksperimen desain one group pretest-posttest design. Menurut Suryana (2010:2), penelitian eksperimen adalah penelitian yang bertujuan untuk menyelidiki kemungkinan sebab akibat dengan cara mengenakan kepada sesuatu atau lebih kondisi perlakuan atau membandingkan hasilnya dengan sesuatu atau lebih kelompok kontrol.

Menurut Sugiyono (2010: 117), populasi adalah wilayah generalisasi yang terdiri atas: subyek yang mempunyai kualitas dan karakteristik tertentu yang ditetapkan oleh peneliti untuk dipelajari dan ditarik kesimpulan. Dalam penelitian ini, populasi yang dimaksudkan adalah siswa kelas XI IPS 3 di SMA Negeri 9 Kota Bengkulu yang berjumlah 27 siswa.

Menurut sugiyono (2010: 118), sampel adalah bagian dari jumlah dan karakteristik yang dimiliki oleh populasi tersebut. Bila populasi besar maka peneliti tidak mungkin mempelajari semua populasi yang besar, penelitian tidak mungkin mempelajari semua yang ada pada populasi, misalnya karena keterbatasan dana, waktu dan tenaga maka peneliti dapat mengambil sampel yang ada pada populasi itu. Peserta didik yang menjadi sampel penelitian berjumlah 8 orang siswa. Kelompok 4-8 orang adalah kelompok yang besarnya sedang yang dapat diselenggarakan dalam rangka bimbingan dan konseling. Kelompok yang sedang besarnya ini biasanya mudah dikendalikan. Di samping itu, dalam kelompok sedang itu dapat dimunculkan keragaman di antara anggota-anggotannya sehingga suasana dinamika kehidupan kelompok dapat "Hangat” (Prayitno, 1995: 28).

\section{Hasil dan Pembahasan}

Dalam menentukan kategori perolehan skor subjek penelitian, diawali dengan mencari mean dan standar deviasi, dengan menggunakan Software Statistical Packages for Social Science (SPSS) versi 17.

Tabel 1

Deskripsi Pre-test

\begin{tabular}{lccc}
\hline Kategori & Interval & Frekuensi & $\%$ \\
\hline Sangat sesuai & $>75$ & - & - \\
Sesuai & $66-74$ & - & - \\
Cukup sesuai & $62-65$ & - & - \\
Tidak sesuai & $50-61$ & 8 & $80 \%$ \\
Sangat tidak sesuai & $\leq 49$ & - & - \\
\hline
\end{tabular}


Hasil pengambilan data awal (Pre-test) dikategorikan 8 orang siswa memiliki interaksi sosial tidak sesuai. Sampel yang termasuk dalam kategori tidak sesuai akan diberikan layanan konseling kelompok. Pada pre-test dapat disimpulkan bahwa siswa yang memiliki interaksi sosial kategori skor antara $50-61$ berjumlah 8 orang dengan persentase sebesar $80 \%$.

Berdasarkan hasil tersebut peneliti mengambil sampel 8 orang siswa yang memiliki interaksi sosial rendah berjumlah 8 orang siswa. Delapan orang siswa tersebut diberi layanan konseling kelompok sebanyak 6 kali.

Setelah diberikan layanan konseling kelompok, angket tentang interaksi sosial yang sebelumnya digunakan dalam pre-test digunakan kembali dalam post-test. Diadakan posttest bertujuan untuk mengukur interaksi sosial siswa setelah mendapatkan layanan konseling kelompok.

\section{Tabel 2}

Deskripsi post-test

\begin{tabular}{lccc}
\hline Kategori & Interval & Frekuensi & \% \\
\hline Sangat sesuai & $>75$ & 1 & $10 \%$ \\
Sesuai & $66-74$ & 4 & $40 \%$ \\
Cukup sesuai & $62-65$ & 3 & $30 \%$ \\
Tidak sesuai & $50-61$ & - & - \\
Sangat tidak sesuai & $\leq 49$ & - & - \\
\hline
\end{tabular}

Menggambarkan adanya peningkatan interaksi sosial siswa yang semula 8 orang siswa berada pada kategori tidak sesuai. 1 orang siswa yang menjadi sangat sesuai, persentase sebesar $10 \%$ dengan interval (>75). 4 orang siswa menjadi sesuai, dengan presentase sebesar 40\% dengan interval (66-74). 3 orang siswa menjadi cukup sesuai, dengan presentase sebesar $30 \%$ dengan interval (62-65).

Penelitian ini menguji pengaruh layanan konseling kelompok terhadap interaksi sosial siswa kelas XI IPS 3 di SMA Negeri 9 Kota Bengkulu. Untuk menguji hipotesis tersebut peneliti menggunakan uji z dengan menggunakan Software Statistical Packages For Social Science (SPSS), dengan uji Wilcoxon Signed Ranks Test untuk melihat apakah ada pengaruh layanan konseling kelompok terhadap interaksi sosial siswa kelas XI IPS 3 di SMA Negeri 9 Kota Bengkulu.

Hipotesis dalam penelitian ini adalah: H0: tidak ada pengaruh layanan konseling kelompok terhadap interaksi sosial siswa kelas XI IPS 3 di SMA Negeri 9 Kota Bengkulu. 
Ha: ada pengaruh layanan konseling kelompok terhadap interaksi sosial siswa kelas XI IPS 3 di SMA Negeri 9 Kota Bengkulu.

Pengujian hipotesis awal (H0) diterima ataupun ditolak dengan aturan: jika nilai Sig. (2tailed $)<0.05$ maka H0 ditolak. Namun, jika nilai Sig. (2-tailed)>0.05 maka H0 diterima.

Uji Z, dapat dilihat nilai Z $(-2,524)$ yang berarti ada peningkatan perolehan skor pretest terhadap perolehan skor post-test. Langkah selanjutnya adalah melihat nilai Sig. (2tailed) adalah 0,012. Maka hipotesis awal (H0) ditolak karena nilai Asymp. Sig. (2-tailed) $0,012<0,05$.

Hasil penelitian ini dapat disimpulkan bahwa ada perbedaan skor sebelum dan sesudah diberikan layanan konseling kelompok yang berarti ada pengaruh layanan konseling kelompok terhadap interaksi sosial siswa kelas XI IPS 3 SMA Negeri 9 Kota Bengkulu.

Konstribusi layanan konseling kelompok di atas, konstribusi layanan konseling kelompok dapat dihitung dengan rumus koefisien determinasi. Berdasarkan perhitungan rumus koefisien determinasi, sumbangan layanan konseling kelompok terhadap interaksi sosial sebesar $18 \%$.

\section{Hasil dan Pembahasan}

Penelitian dilakukan dari tanggal 1 April 2018 sampai dengan 30 April 2018. Pada tanggal 3 April 2018 di lakukan pre-test kepada siswa kelas XI IPS 3. Diketahui setelah diberikan angket interaksi sosial terdapat 8 orang siswa (TS, ADP, ANS, FNY, QRI, RDL, STA, SLY) dalam kategori tidak sesuai dengan skor antara 50-61. Berdasarkan hasil pre-test yang telah dilakukan, skor rata-rata pre-test menunjukkan interaksi sosial siswa yang rendah membutuhkan perlakuan dan terwujudnya dinamika kelompok dalam kegiatan konseling kelompok agar interaksi sosial siswa dapat meningkat.

Berdasarkan hasil uji hipotesis yang telah diberikan, diperoleh hasil bahwa terdapat pengaruh yang signifikan antara layanan konseling kelompok terhadap interaksi sosial siswa yang memperoleh perlakuan konseling kelompok dengan nilai yang signifikan 0,012 yang berarti $0,012<0,05$ dengan nilai $Z=-2,524$. Jadi dapat diketahui bahwa $\mathrm{H} 0$ ditolak dan $\mathrm{Ha}$ diterima, yang berarti ada pengaruh yang signifikan konseling kelompok terhadap interaksi sosial siswa yang memperoleh perlakuan konseling kelompok yaitu TS, ADP, ANS, FNY, QRI, RDL, STA, SLY. 
Hasil yang diperoleh dalam penelitian ini relevan dengan penelitian yang dilakukan oleh Nia Novianti (2017) yang berjudul efektivitas layanan konseling kelompok dengan teknik analisis transaksional dalam meningkatkan kemampuan interaksi sosial siswa SMP Bandar Lampung. Dalam penelitian ini dapat disimpulkan bahwa ada pengaruh layanan konseling kelompok terhadap interaksi sosial siswa. Hal ini dapat diketahui dari meningkatnya interaksi sosial siswa setelah diberikan layanan konseling kelompok.

Selanjutnya, hasil penelitian ini sesuai dengan hasil penelitian Norma Indah Pratiwi (2015) yang berjudul Peningkatan Interaksi Sosial dengan Menggunakan layanan konseling kelompok. Pada hasil penelitian Norma Indah Pratiwi dikatakan bahwa kemampuan interaksi sosial siswa dapat ditingkatkan dengan menggunakan konseling kelompok.

Berdasarkan hasil penelitian, kajian teori, dan penelitian yang relevan maka dapat disimpulkan bahwa layanan konseling kelompok berpengaruh terhadap peningkatan interaksi sosial siswa SMA Negeri 9 Kota Bengkulu.

\section{Kesimpulan}

Berdasarkan hasil penelitian pengaruh layanan konseling kelompok terhadap interaksi sosial siswa kelas XI IPS 3 di SMA Negeri 9 Kota Bengkulu, dapat disimpulkan sebagai berikut:

1. Interaksi sosial siswa sebelum diberikan perlakuan berupa konseling kelompok memiliki interaksi sosial rendah. Jumlah rata-rata skor pre-test pada kelompok eksperimen adalah 52. Berarti interaksi sosial siswa tergolong rendah.

2. Interaksi sosial siswa setelah diberikan layanan konseling kelompok pada kategori sangat sesuai. Jumlah rata-rata skor post-test adalah 70 berarti interaksi sosial siswa mengenai interaksi sosial dalam tergolong sesuai (baik).

3. Ada pengaruh dari layanan konseling kelompok terhadap interaksi sosial siswa. Hal ini dapat dibuktikan dengan uji Wilcoxon dengan nilai Z, yaitu $-2,524$ dengan signifikan adalah 0,012 yang berarti nilai signifikan 0,012 <0,05.

\section{Daftar Pustaka}

Novianti, N. (2017). Efektivitas Layanan Konseling Kelompok dengan Teknik Analisis Transaksional dalam Meningkatkan Kemampuan Interaksi Sosial Peserta Didik Kelas VIII SMP Negeri 18 Bandar Lampung Tahun Pelajaran 2016/2017.(Skripsi tidak dipublikasikan). Bimbingan dan Konseling Fakultas Tarbiyah dan Keguruan Institut Agama Islam Negeri Raden Intan Lampung. 
Pratiwi, I. (2015). Peningkatan Interaksi Sosial Dengan Menggunakan Layanan Konseling Kelompok Pada Siswa Kelas VIII di SMP Negeri 3 Natar Tahun Pelajaran 2014/2015.(Skripsi tidak dipublikasikan). Bimbingan dan Konseling Fakultas Ilmu Pendidikan Universitas Negeri Lampung.

Prayitno. (2004). L.1-L.9 Seri Kegiatan Pendukung Konseling. Padang: UNP Padang.

Prayitno. (1995). Layanan Bimbingan dan Konseling Kelompok (Dasar dan Profil). Padang: Ghalia Indonesia.

Riansyah, H. (2017). Layanan bimbingan kelompok dalam meningkatkan interaksi sosial siswa. Jurnal Bimbingan dan Konseling. 1(1), 47-52.

Soekanto. (2010). Sosiologi suatu pengantar. Jakarta: Rajagrafindo Persada.

Sugiyono. (2010). Metodologi Penelitian Pendidikan: Pendekatan Kuantitatif, Kualitatif dan $R \& D$. Bandung: ALFABETA.

Sukardi, K. D. (2008). Pengantar Pelaksanaan Program Bimbingan dan Konseling Di Sekolah. Jakarta: Rineka Cipta.

Suryana. (2003). Pedoman Praktis. Jakarta: Selemba Empat.

Walgito, B. (1999). Psikologi Sosial Suatu Pengantar. Yogyakarta: Andi. 